\title{
Gövde alçıları ve endikasyonları
}

\author{
Body casts and indications
}

\author{
Mustafa Caner Okkaoğlu, İsmail Demirkale, Murat Altay
}

Sağlık Bilimleri Üniversitesi, Ankara Keçiören Eğitim ve Araştırma Hastanesi, Ankara

\begin{abstract}
Gövde alçısı, 19. yüzyıldan beri uygulanmasına rağmen günümüzde daha çok erken başlangıçlı skolyoz tedavisinde kullanılmaktadır. Erken başlangıçlı skolyozda tedavi edici özelliği, resmi olarak ilk kez 1979 yılında Londra Skolyoz Sempozyumu'nda vurgulanmıştır. Uygun zamanda başlandığında, ileri olmayan eğriliklerde tamamen tedavi edici iken, ileri derecede eğriliklerde eğriliğin ilerlemesini durdurma ve ameliyatın geciktirilmesinde etkili olması, gövde alçısının en önemli özellikleridir. Bu sayede, erken ameliyatın komplikasyonlarının azaltılması sağlanmaktadır. Brakiyal pleksus hasarları, kraniyal sinir bozuklukları ve superior mezenterik arter sendromu, genel anestezi altında yapılan alçılamanın başlıca akut komplikasyonlarıdır. Bir diğer komplikasyon olarak, bir çalışmada alçılama sırasında hastalarda maksimum inspiratuvar basıncın neredeyse iki kat arttığı gösterilmiştir. Bu nedenle, uygun teknik ve uygun alçı gevşetmeleri şarttır. Son yıllarda yapılan çalışmalarla konjenital skolyozda ve nöromusküler skolyozda dahi etkinliği gösterilen seri alçılama, günümüzdeki modern cerrahi yöntemlere rağmen, hem daha kolay olması ile hem de daha az komplikasyonla, mantıklı ve tercih edilmesi gereken bir yöntemdir.
\end{abstract}

Anahtar sözcükler: erken başlangıçıı skolyoz; seri alçılama; gövde alçısı tekniği

\begin{abstract}
Nowadays, body cast is especially used in the treatment of early onset scoliosis although it has been practiced since 19th century. Curative effect of serial body casting on early onset scoliosis was first officially emphasized in London Scoliosis Symposium in 1979. If casting could be started in the proper time, it has therapeutic effect on mild and moderate scoliosis, or has a preventive effect on the progression of severe scoliosis and delay of the surgery. In this way, it is possible to reduce the complications of early surgery. Brachial plexus injury, cranial nerve palsy, and superior mesenteric artery syndrome are the major acute complications of casting with general anesthesia. In a study, a different complication, which is about two times increased maximum inspiratory pressure during casting, was reported. Therefore, careful casting with proper technique and release of the certain parts are essential. Finally, despite of the existence of modern surgical techniques, body cast which is effective even in congenital and neuromuscular scoliosis besides early onset scoliosis as showed in recent studies, is a rational and preferable method with less complications.
\end{abstract}

Key words: early onset scoliosis; serial casting; body cast technique

\section{GiRiş VE TARIHÇE}

Gövde alçısı; cerrahi tedavi seçenekleri yok iken, skolyoz tedavisinin asıl yöntemi olarak 19. yüzyıldan beri kullanılmasına karşın, günümüzde sadece erken başlangıçlı skolyozun tedavisinde uygulanmaktadır. Bu konuda en eski yayın; 1877 yılında Lewis Sayre'nin yayımladığı, spinal deformitelerin traksiyon ile düzeltilip, düzeltmenin alçı ile korunduğu ve tecrübelerini anlattığı yayındır. ${ }^{[1]}$ Bundan sonra ise Bradford ve Brackett, 1893 yılında, skolyozda lateral baskı ile alçı

uygulaması konusundaki deneyimlerini aktarmışlardır. [2] Cerrahi füzyona yardımcı olmak için uygulanacak gövde alçılamasını ise Hibbs 1924 yılında önermiştir. ${ }^{[3]}$ Risser, 1955 yılında, düzeltici alçılama tekniğini daha ayrıntılı bir şekilde tanımlamış, eğriliğin düzeltilmesi için özel bir masa tasarlamıştır. ${ }^{[4]}$

Segmental spinal enstrümantasyon tekniklerinin gelişmesinden sonra; skolyoz ameliyatları sırasında elde edilen düzeltmeyi koruma amaçlı alçılama, anlamsız hale gelmiştir. ${ }^{[5]}$ Cotrel ve Morel, 1964 yılında

- İletişim adresi: Prof. Dr. Murat Altay, M. Caner Okkaoğlu, Pınarbaşı Mah., Sanatoryum Caddesi Ardahan Sokak D:25, 06280 Keçiören, Ankara Tel: 0312 - 3569000 e-posta: canerokkaoglu@gmail.com

- Geliş tarihi: 1 Ağustos $2018 \quad$ Kabul tarihi: 1 Ağustos 2018 
Risser'in tekniğinden derotasyonel kuvvetin uygulanış yöntemi ile ayrılan yeni bir alçılama tanımlamıştır. ${ }^{[6]}$ Ancak, cerrahi tedavi yöntemlerindeki gelişmelerden sonra juvenil ve adolesan skolyozda kullanımı gittikçe azalmış, seri alçı uygulamasının sadece erken başlangıçı idiyopatik spinal deformitelerin düzeltilmesinde etkili olduğu bulunmuştur. Günümüzde, özellikle cerrahi tedaviyi geciktirmek için, breysle kontrol edilemeyen eğriliğe sahip hastalarda endikedir. Bu yazarların önerileri ışığında, erken başlangıçlı skolyozda seri gövde alçılamasının yeri, resmi olarak ilk 1979 yılında Londra'da Altıncı Skolyoz Sempozyumunda, Mehta ve Morel tarafindan anlatılmıştır. ${ }^{[7]}$ Bundan 25 yıl sonra ise Mehta 136 infantil ilerleyici skolyoz hastasının dahil edildiği ileriye dönük çalışmasını yayımlamıştır. Mehta bu çalışmasında Cotrel ve Morel'in yöntemini kullanmıştır, fakat derotasyon için kayışları kullanmamış, bunun yerine alçı yapılırken kot çıkıntısına manuel baskı yapılıp mold edilerek derotasyon sağlamıştır. Alçılama, erken zamanda, orta ve az derecede eğriliklerde uygulandığında tamamen düzelmiştir. Geç başlandığında ve şiddetli eğriliklerde ise, tamamen düzelmese de, bu eğriliklerde belirgin bir azalma elde edilmiştir. ${ }^{[8]}$

Gövde alçılarının, erken başlangıçlı idiyopatik skolyozda cerrahi tedaviyi geciktirmede breyslerin başarılı olamaması sonrasında kullanılması önerilmektedir. Eğriliğin derecesi ve sertliğinin artması sonrasında, eğer çocuk breysi tolere edemez hale gelirse, anestezi altında yapılacak seri gövde alçılaması sayesinde omurganın daha esnek olması ile, eğrilikte ciddi bir düzelme sağlanabilir. Aileler için de gövde alçıları, kullanımı kolay ve çıkartılması takılması gerekmeyen bir yöntem olduğu için, özellikle uyum sağlayamayacak küçük çocuklarda breys kullanımının zorluklarını ortadan kaldırır. Her ne kadar geciktirme amaçlı bir tedavi olarak görülse de, alçılamanın kendisinin de yapılan çalışmalarda tek başına tedavi edici olduğu gösterilmiştir. ${ }^{[9]}$

Gövde alçılamaları her ne kadar farklı yöntemler ile yapılabilse de, takipleri benzerdir. İki yaşın altındaki çocuklarda her 2-3 ayda bir anestezi altında yapılır ve en az beş alçılama önerilir. Breyse geçilene kadar düz bir omurga hedeflenir. İki yaş üstünde ise alçılama 3-4 ayda bir yapılır. Nüks gerçekleşen skolyoz olgularında ise, deformiteyi esnetmek ve tekrar düzeltmek için dört aylığına gövde alçısı yapılabilir. ${ }^{[9]}$ Seri alçılamanın dezavantajı, yaşı küçük olan hastanın çok sık genel anestezi almasıdır. Fakat yaşın küçük olması bize, en hızlı spinal büyümenin olduğu ilk iki yılda seri alçılamayla çok hızlı bir düzeltme gücü sağlar. ${ }^{[10]}$ Mehta, alçılama sırasında traksiyon uygulayarak hem omurganın uzayarak düzelmesini hem de derotasyonu sağlamıştır. Ek olarak, kot çıkıntılarına manuel baskı uygulayarak derotasyonu daha da düzeltmiş ve alçılama ile elde edilen düzeltmenin korunmasına çalışmıştır. Mehta, geniş serisinde, en hızlı spinal büyümenin olduğu bu dönemde yapılan bu manipülasyon ile, alçılama sonrası büyümenin düzeltmeye yardımcı olduğunu göstermiştir. ${ }^{[8]}$

Alçılamada büyümenin deformitenin düzelmesine yardımcı olması, tedavinin erken başlamasının sonuçlara etkisi hakkında da bize fikir vermektedir ki; hem Mehta'nın çalışmasında hem daha sonra yapılan çalışmalarda, tedavinin başladığı yaşın sonuçları etkileyen başlıca faktör olduğu gösterilmiştir. Mehta, 27-35 eğriliği olanlar ve $15-21$ aylık olan hastalarda eğriliğin seri alçılamayla tamamen düzeldiğini, 47-53 ${ }^{\circ}$ egrili olanlar ve 27-34 aylık olan hastalarda ise tam olarak düzelmediğini, buna karşılık Sander ve ark., $60^{\circ}$ 'ye kadar eğriliği olan ve iki yaşından önce tedavisi başlanan hastalarda eğriliğin düzeldiğini göstermişlerdir. ${ }^{[8,11]}$ Eğriliği tam olarak düzelmeyen hastalarda bile alçılama yarar sağlamaktadır. Böylece, hem eğriliğin ilerlemesi durdurulup yeteri kadar olmasa bile gerileme sağlanabilir hem de küçük çocukta birçok komplikasyonu olan cerrahinin ertelenmesi sağlanır. Nitekim Fletcher ve ark. ile Waldron ve ark. yaptıkları çalışmalarda, bazı hastalarında düzelmeyi, kalan hastalarda ise cerrahi tedavinin ertelenmesini sağladıklarını bildirmişlerdir. ${ }^{[12,13]}$ Johnston ve ark., 2013 yılında yaptıkları çalışmalarında, büyüyen rod ile enstrümantasyon ve seri alçılamayı karşılaştırmışlardır. Enstrümantasyon grubunda alçılama grubuna göre eğrilikte daha belirgin düzelme gözlenirken, alçılamaya göre çok daha fazla komplikasyon meydana gelmiştir. Ayrıca bu çalışmada, alçılama için en çok önerilen yaş grubundan daha büyük çocuklara alçı yapılmasına rağmen, bazı hastalarda düzelme sağlanıp çoğu hastada da en azından eğriliğin artması engellenmiş ve cerrahi müdahalenin ertelenmesi sağlanmıştır. Daha önce yapılan bir çalışmada da, büyüyen rod tedavisiyle her yıl komplikasyon oranının yaklaşık \%24 arttığı göz önüne alınırsa, cerrahinin ertelenmesinin ne kadar önemli olduğu anlaşılacaktır. ${ }^{[14]}$

Seri gövde alçılaması, konjenital skolyozda da erken başlangıçlı idiyopatik skolyozda olduğu kadar olmasa da etkili bir yöntem olarak görünmektedir. Asıl sorun yapısal bir anomali olduğu için, alçılama majör eğriliğe belirgin olarak etki edemese de, oluşan kompansatuvar eğriliğin ilerlemesini engelleyebilir. ${ }^{[9]}$ Demirkıran ve ark., 11 hastalık serilerinde konjenital eğrilikte ortalama 15 , kompansatuvar eğrilikte 16 , hatta sagittal deformitede ortalama $12^{\circ}$ 'lik bir düzelme sağlamışlardır. ${ }^{15]}$ Eğriliğin son ölçümleri yapıldığında ise doğal olarak tam bir düzelmenin sağlandığı 

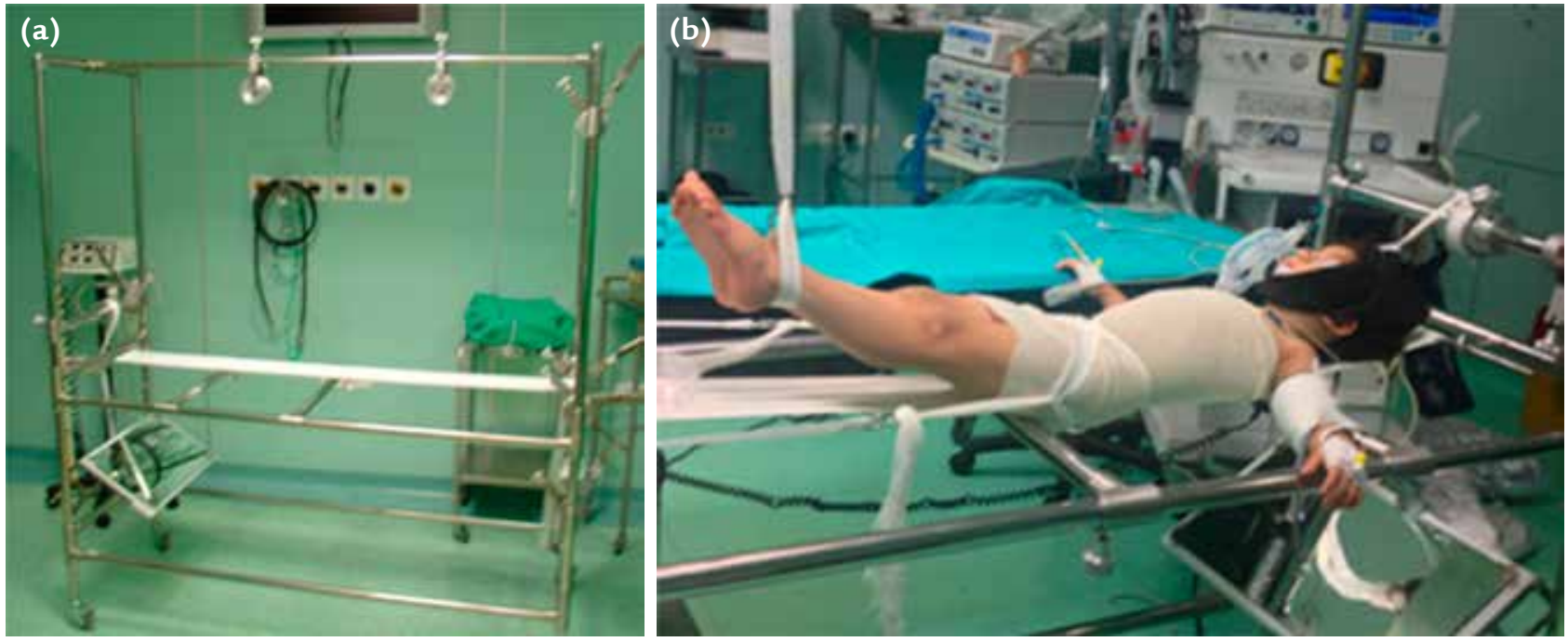

Şekil 1. a, b. Gövde alçılama masası (a). Traksiyon altında manipülasyon ve alçılama için hastanın hazırlanması (b). (Dr. Gökhan Demirkıran'ın arşivinden)

söylenememiştir, fakat eğriliğin kontrol edilebildiği ve cerrahinin ertelenebildiği gösterilmiştir. Yine Cao ve ark., 2017 yılında yaptıkları çalışmada, hem konjenital hem de erken başlangıçlı skolyozlarda alçılamayı incelemişler; erken başlangıçı olanlarda ortalama $47,53^{\circ}$ 'lik düzelme elde edilirken, konjenital skolyoz grubunda ortalama $20,52^{\circ}$ 'lik düzelme sağlamışlar; alçılamanın erken başlangıçı skolyozda tedavi edici, konjenital skolyozda ise cerrahiyi geciktirici bir yöntem olduğu sonucuna varmışlardır. ${ }^{[16]}$

\section{ALÇILAMA YÖNTEMi}

Seri gövde alçılama yöntemleri ile ilgili, Risser'den itibaren birçok yöntem tanımlanmıştır. ${ }^{[4,6,7,17]}$ Günümüzde ise, teknikler arasında küçük farklılıklar olsa da, Mehta'nın tanımladığı yöntem temel alınmaktadır. Burada, Dede ve ark.'nın 2016 yılında tanımladığı alçılama anlatılmıştır. Seri gövde alçılama$\mathrm{da}$, anestezi olarak genel anestezi tercih edilir. Pelvik, baş tutucuları ve traksiyon kayışları olan uygun alçı masası hazırlanır (Şekil 1). Entübasyon sonrasında, boyun askısından traksiyon yapılırken kaza ile yanaklarda ve dilde yaralanma olmaması için ağız içine ısırma engelleyici aparat yerleştirilir. Hastaya alçı gömleği ya da uygun alçı sitokineti giydirilir, fakat alçının çok sıkı olmaması için bunların altına da havlu katlar yerleştirilir. Kulakları ve gözleri koruması için bir havlu kullanılır; bu, traksiyon sırasında kulakları basınçtan, gözleri de düzeltme sırasında ortaya çıkan tozdan korur. Daha sonra boyun askısı oksiput ve çenenin altından, uzun kayışlar ise her iki taraftaki iliak kanatların üzerinde hastanın belinden geçirilir ve hasta alçı masasına alınır. Anestezist tarafından hastanın başı, asistanlar tarafından da hastanın gövde ve bacakları desteklendikten sonra masanın sırt desteği çıkarılır; bir yatay destek sakrumun, bir diğeri ayak bileklerinin altına, üçüncüsü de baş altına hastanın ağırlığını desteklemek için yerleştirilir. Tüm baskı noktaları pamuk pedler ile desteklenir. Illk önce hafif bir traksiyon uygulanır ve dişli çark ile sistemin gerginliği sağlanır. Daha sonra, eğriliğin konkav tarafına pelvik kayışlar ile daha fazla traksiyon uygulanır. Bu sırada cerrahın aşırı traksiyon açısından dikkatli olması gerekir. Eğer omuz askıları da kullanılacaksa, bu bölgeye de dörtbeş kat pamuk destek konulmalıdır. Uygun traksiyon sağlandıktan sonra superior anterior iliak krestlere iki adet dairesel keçe konularak üzerinden dört kat alçı sarılmaya başlanır. Alçının pelvik kısmı dayanak noktasıdır; bu nedenle alçı iliak kanatlar üzerine iyi mold edilmelidir. Daha sonra, yukarı doğru sarılan alçı avuç içi ile, torakal eğriliğin apeksine bağlı kot çıkıntılarına posteriordan anteriora, lateralden mediyale doğru baskı yapılarak mold edilir (Şekil 2). Bu mold yapılırken, karşı destek almak için karşı iliak kanat el ile desteklenir. Üçüncü destek noktası olarak da asistan elini toraksın anterolateral tarafına koyar. Konveksitenin posterolateralinde belirgin mold görülmelidir. Daha sonra alçıyı güçlendirmek için üzerine fiberglas alçı uygulanabilir. Bu alçıdan sonra hedef düzeltme miktarı \%50'den fazladır; ön-arka grafide düzeltme kontrol edilir. Daha sonra, torako-abdominal bölgede 


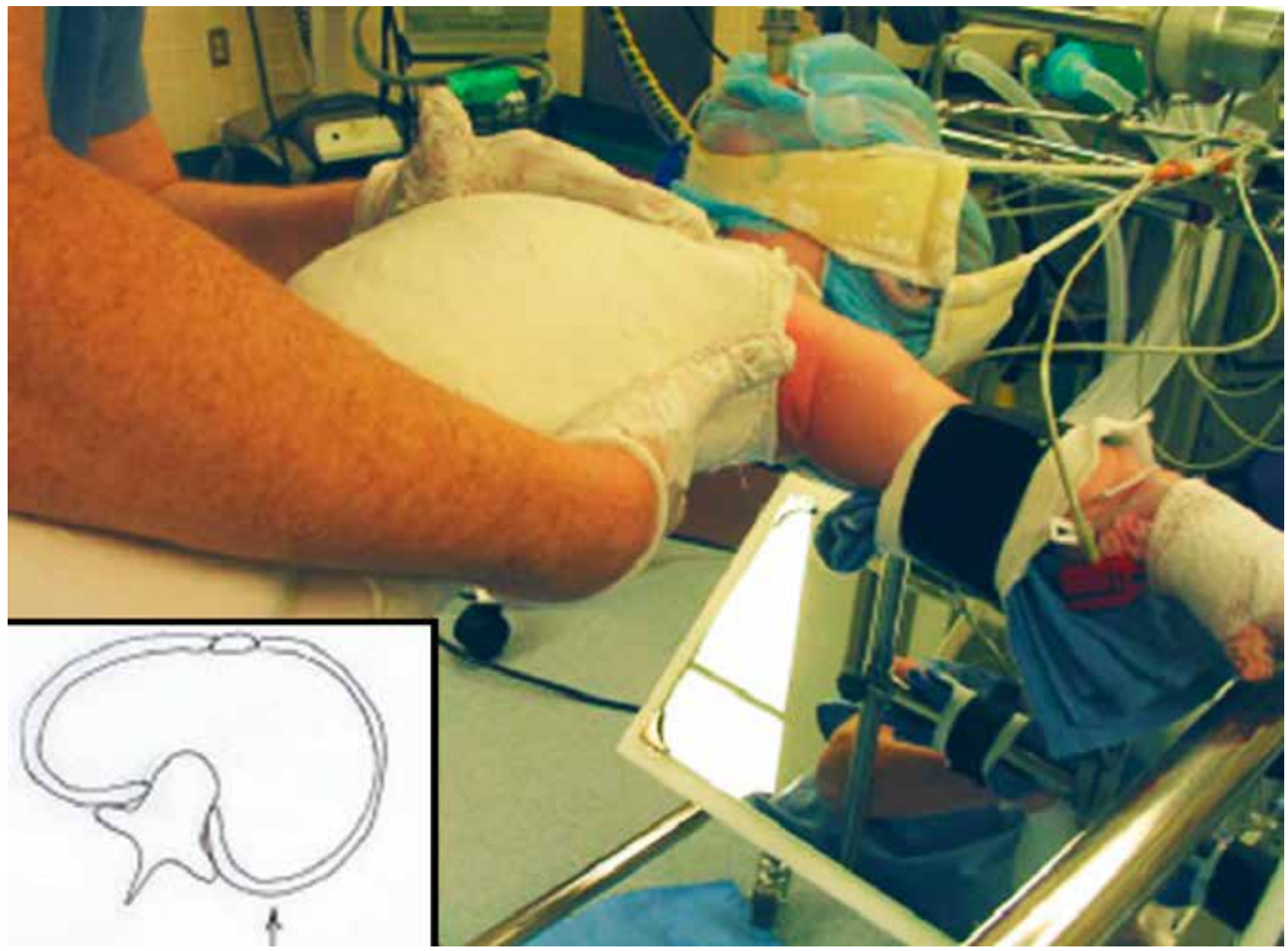

Şekil 2. Sarılan alçı avuç içi ile, torakal eğriliğin apeksine bağlı kaburga çıkıntılarına posteriordan anteriora, lateralden mediyale doğru baskı yapılarak mold edilir. (Dr. Gökhan Demirkıran'ın arşivinden)

abdomen ve diyaframın rahat hareket etmesine izin vermesi için mantar şeklinde kapak açılır. Yine, eğriliğin konkav tarafında apikal kotların üzerinden daha fazla derotasyona izin vermesi için posterolateral bir kapak açılır (Şekil 3). Daha sonra alçının, kalça hareketi için etek kısmı, omuz hareketleri için koltuk altları, kafa ve çene hareketlerini kısıtlamaması için de boyun kısmı yeterince kesilir. ${ }^{[17]}$

\section{KOMPLIKASYONLAR}

Brakiyal pleksus hasarları, kraniyal sinir bozuklukları ve superior mezenterik arter sendromu, genel anestezi altında yapılan alçılamanın başlıca akut komplikasyonlarıdır. Bilişsel bozukluğu olan hastalarda kot ve diğer kemik çıkıntılarındaki bası yaraları ise uzun dönem komplikasyonlar olarak görülebilir. Bu nedenle, bilişsel bozukluğu olan hastalarda alçılama göreceli olarak kontrendikedir. ${ }^{[9]}$ Yine, subklaviyen arter trombozu gibi ciddi bir komplikasyon da olgu sunumu şeklinde literatürde yayımlanmıştır. ${ }^{[18]}$ Bir diğer çalışmada, alçılama sırasında hastalarda maksimum inspiratuvar basıncın neredeyse iki kat arttı̆̆ı gösterilmiştir. Fakat bunun, alçı üzerinde pencereler açıldığında büyük oranda düzeldiği görülmüş̧ür. Yine de, alçı yapılan hastalarda, alçı öncesine göre bu basınç \%32 daha fazla bulunmuştur. ${ }^{[19]} \mathrm{Bu}$ nedenle, alçı sonrasında hastaların solunumlarının takip edilmesi, özellikle altta yatan ek rahatsızlığı olanlarda çok önemlidir.

\section{SONUÇ}

Seri gövde alçılaması, özellikle erken başlangıçlı idiyopatik skolyozda olmak üzere, nöromusküler ve konjenital skolyozda etkili bir tedavi yöntemidir (Şekil 4). Eğriliği çok büyük olmayan hastalarda tek başına 

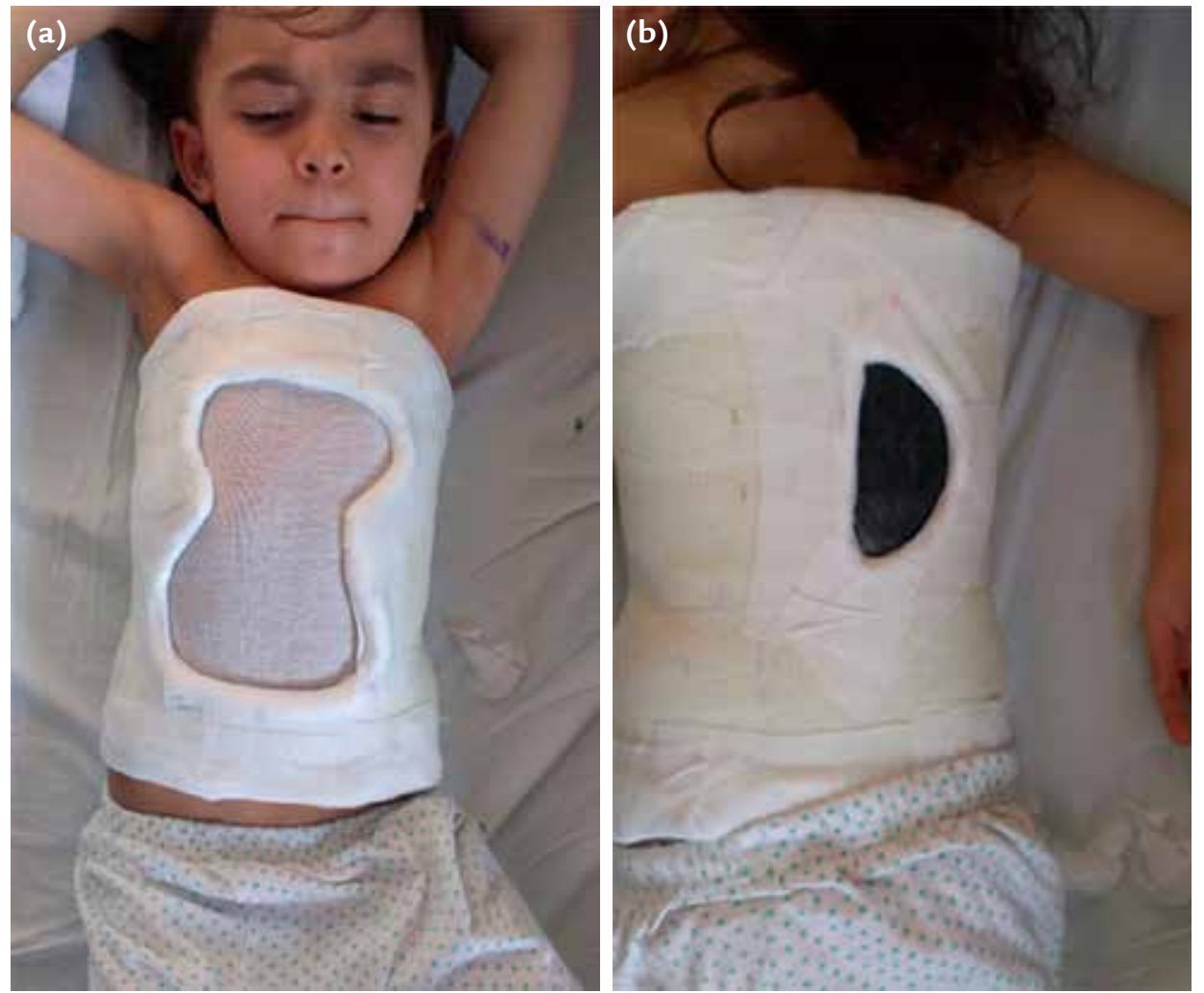

Şekil 3. a, b. Torako-abdominal bölgede anteriordan abdomen ve diyaframın rahat hareket etmesine izin vermesi için mantar şeklinde kapak açılır (a). Eğriliğin konkav tarafında apikal kaburgaların üzerinden daha fazla derotasyona izin vermesi için posterolateral bir kapak açılır (b). (Dr. Gökhan Demirkıran'ın arşivinden)
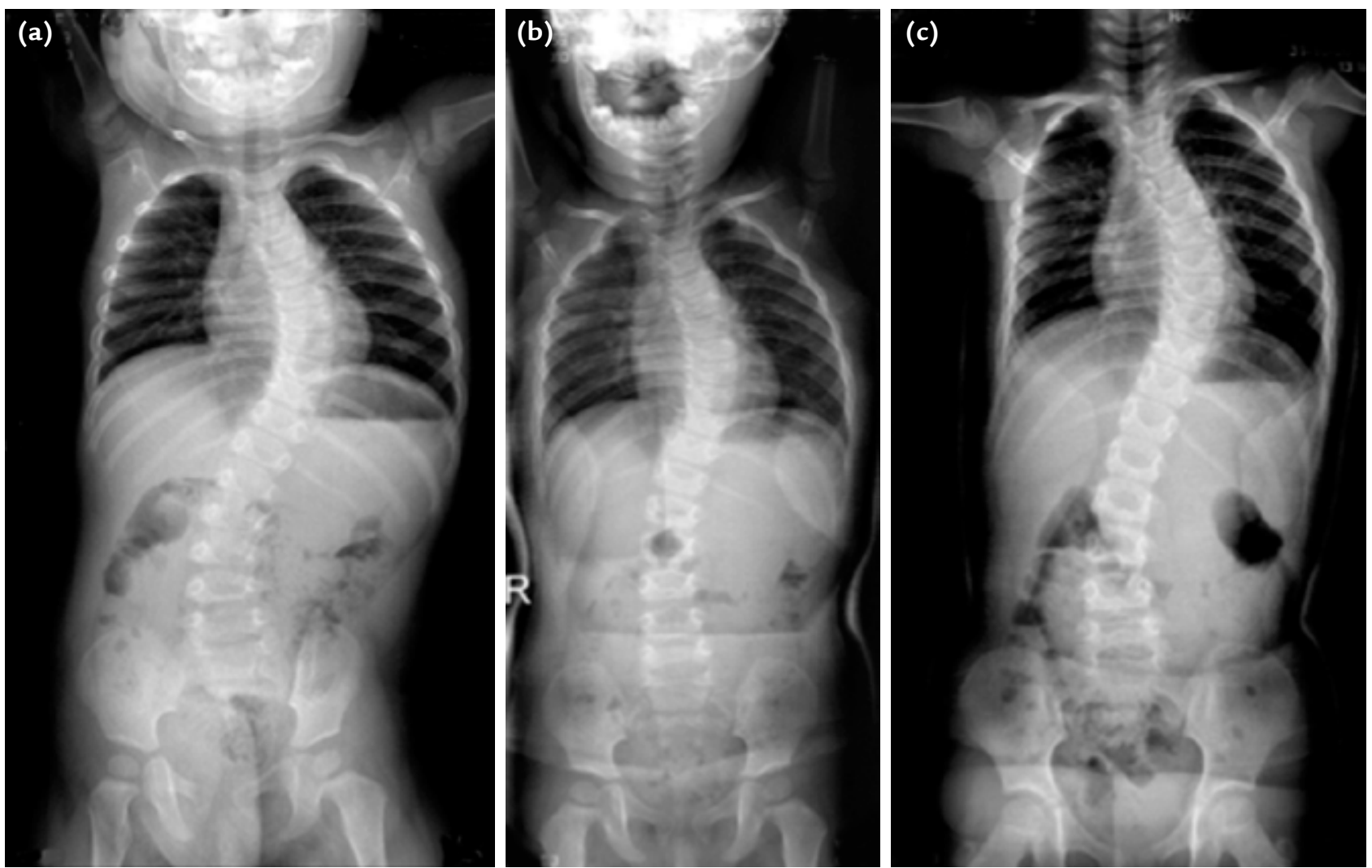

Şekil 4. a-c. Alçılama öncesi bir yaşında erken başlangıçlı skolyoz olgusu (a). Alçılama sonrası 4. ayda düzelme göstermiş (b), üç yıl sonra düzelme bir miktar gerilese de en azından ilerleme durdurulmuştur (c). (Dr. Gökhan Demirkıran'ın arşivinden) 
tedavi edici bir yöntem iken, şiddetli eğriliklerde eğriliği durdurucu ve azaltıcı etkisi mevcuttur. Bu sayede, erken cerrahi tedaviyi engellemekte ve buna bağlı oluşabilecek birçok komplikasyonun önüne geçmektedir. Günümüzdeki modern cerrahi yöntemlere rağmen, hem daha kolay hem daha az komplikasyonu olan seri alçılama, erken başlangıçlı skolyoz tiplerinde mantıklı ve tercih edilmesi gereken bir yöntemdir.

\section{KAYNAKLAR}

1. Sayre LA. Spinal Disease and Spinal Curvature, Their Treatment by Suspension and the Use of the Plaster of Paris Bandage. London: Smith, Elder \& Co.; 1877.

2. Bradford EH, Brackett EG. Treatment of lateral curvature by means of pressure correction. Boston Med Surg J 1893;128(19):463-8. Crossref

3. Hibbs RA. A report of fifty-nine cases of scoliosis treated by the fusion operation. By Russell A. Hibbs, 1924. Clin Orthop Relat Res 1988;(229):4-19.

4. Risser JC. The application of body casts for the correction of scoliosis. Instr Course Lect 1955;12:255-9.

5. Luque ER. Segmental spinal instrumentation for correction of scoliosis. Clin Orthop Relat Res 1982;(163):192-8. Crossref

6. Cotrel Y, Morel G. The elongation-derotation-flexion technic in the correction of scoliosis. Rev Chir Orthop Reparatrice Appar Mot 1964;50:59-75.

7. Mehta M, Morel G. The non-operative treatment of infantile idiopathic scoliosis. In: Zorab P, Siegler D, editors. Sixth symposium on scoliosis; September 17-18, 1979. London: Academic Press; 1980. p.71-84.

8. Mehta $\mathrm{MH}$. Growth as a corrective force in the early treatment of progressive infantile scoliosis. J Bone Joint Surg Br 2005;87-B(9):1237-47. Crossref

9. Richards BS, Sucato DJ, Johnston CE. Scoliosis. In: Herring JA, editor. Tachdjian's Pediatric Orthopaedics. Vol. 1-5. USA. Elsevier Saunders; 2014.
10. Dimeglio A. Growth of the spine before age 5 years. J Pediatr Orthop B 1993;1(2):102-7. Crossref

11. Sanders JO, D'Astous J, Fitzgerald M, Khoury JG, Kishan $\mathrm{S}$, Sturm PF. Derotational casting for progressive infantile scoliosis. J Pediatr Orthop 2009;29(6):581-7. Crossref

12. Fletcher ND, McClung A, Rathjen KE, Denning JR, Browne $\mathrm{R}$, Johnston CE 3rd. Serial casting as a delay tactic in the treatment of moderate-to-severe early-onset scoliosis. J Pediatr Orthop 2012;32(7):664-71. Crossref

13. Waldron SR, Poe-Kochert C, Son-Hing JP, Thompson GH. Early onset scoliosis: the value of serial risser casts. J Pediatr Orthop 2013;33(8):775-80. Crossref

14. Bess S, Akbarnia BA, Thompson GH, Sponseller PD, Shah SA, El Sebaie H, Boachie-Adjei O, Karlin LI, Canale S, PoeKochert C, Skaggs DL. Complications of growing-rod treatment for early-onset scoliosis: analysis of one hundred and forty patients. J Bone Joint Surg Am 2010;92(15):253343. Crossref

15. Demirkiran HG, Bekmez S, Celilov R, Ayvaz M, Dede O, Yazici M. Serial derotational casting in congenital scoliosis as a time-buying strategy. J Pediatr Orthop 2014;35(1):43-9. Crossref

16. Cao J, Zhang X, Sun N, Guo D, Qi X, Bai Y, Sun B. The therapeutic characteristics of serial casting on congenital scoliosis: a comparison with non-congenital cases from a single-center experience. J Orthop Surg Res 2017;12(1). Crossref

17. Dede O, Sturm PF. A brief history and review of modern casting techniques in early onset scoliosis. J Child Orthop 2016;10(5):405-11. Crossref

18. Badlani N, Korenblit A, Hammerberg K. Subclavian vein thrombosis after application of body cast. J Pediatr Orthop 2013;33(1):e1-3. Crossref

19. Dhawale AA, Shah SA, Reichard S, Holmes L Jr, Brislin R, Rogers K, Mackenzie WG. Casting for infantile scoliosis: the pitfall of increased peak inspiratory pressure. J Pediatr Orthop 2013;33(1):63-7. 